\title{
Un círculo filosófico-literario de finales del XVII en Inglaterra: textos representativos
}

\section{(A philosophical-literary circle in the late $17^{\text {th }}$ century in England: selected texts)}

\author{
ÁNGELES GaRcía CALDERÓN \\ (Universidad de Córdoba)
}

Fecha de recepción: 28 de enero de 2010

Fecha de aceptación: 5 de marzo de 2010

Resumen: Trabajo que analiza la actividad del círculo intelectual agrupado en torno a Mary Astell; se trata normalmente de poetas, aunque también las hay que se dedican a la medicina o a la lengua: Lady Mary Chudleigh, Elizabeth Thomas, Judith Drake, Elizabeth Elstob y Lady Mary Wortley Montagu. Asimismo, se estudia brevemente como miembro de pleno derecho de este grupo al clérigo y filósofo inglés John Norris, que mantuvo una importante correspondencia con Astell. Un sucinto análisis de la figura de cada miembro da paso a una muestra de su obra, consistente generalmente en un poema, representativo de sus inquietudes como componente del grupo.

Palabras clave: Mujeres, Género, Poesía inglesa, Traducción.

Abstract: This paper tries to analyse the activity of the intellectual work in which Mary Astell was in; this group used to be composed by some women poets, that studied also Medicine or Language, as it may the case of some women such as Lady Mary Chudley, Elizabeth Thomas, Judith Drake, Elizabeth Elstob and Lady Mary Wortley Montagu. In addition, we will try to study the figure of the philosopher and clergyman, John Norris; he is one of the members of the group, who had a very important correspondence with Mary Astell. Furthermore, we will study each member of this group, by means of the analysis of part of his works, in most of the cases a representative poem.

Key words: Women, Gender, English poetry, Translation.

\section{INTRODUCCIÓN}

Desde la difusión de Sixteen Revelations of Divine Love (h. 1393) de Julian of Norwich, que parece ser el primer libro escrito por una mujer en inglés, y la aparición en la escena literaria de escritoras como Katherine Philips (que nace en 1632) y Anne Finch, la condesa de Winchilsea (que muere en 1720), transcurren varios siglos, en los que se han ido gestando 
firmes identidades y voluntades de imponer una escritura propia, a pesar de todas las limitaciones que el 'sexo fuerte' impone a las mujeres. Si la obra de Julian of Norwich consiste sólo en la revelación de visiones la aparición de Katherine Philips, Aphra Behn y Anne Finch contribuye a la gestación de lo que luego se considerará el canon de la poesía femenina, que podemos situar entre el comienzo de la Restauración (1660) y la publicación de la obra de Finch: Miscellany Poems, on Several Occasions. By a Lady (1713). Con la entrada en escena de Philips y Behn las mujeres empiezan a ser consideradas como importantes en su profesión y no como simple advenedizas en un mundo de hombres; a pesar de sus caracteres y aptitudes tan distintas ante la sociedad las dos autoras llegan a imponer, por distintos caminos, sus escritos convirtiéndolos en algo apreciado y valorado por el sexo opuesto, basado en los ejes que podríamos denominar "gender", "class" y "literary production". Sus escritos ya pueden verse como transgresores para su época: una por plasmar en sus poemas un tipo de amistad al propio sexo que va más allá de lo que hasta entonces era usual; la otra por su libre albedrío, que la lleva a no respetar los códigos imperantes de "gender" y "sexuality" en sus escritos, atreviéndose incluso con la traducción de autores clásicos que hasta entonces había sido algo privativo de los hombres.

Junto a ellas, cierra el círculo de mujeres precursoras en la defensa de sus derechos Anne Finch, cuyos poemas ya figuran, del modo más natural y sin levantar reticencia alguna, en todas las antologías al uso y sobre la cual coincide la opinión de buena parte de la crítica al considerarla la mejor poetisa de su centuria ${ }^{1}$; la condesa de Winchilsea se inspira en las fuentes clásicas y no desdeña los trabajos de sus coetáneos: Milton, Marvell, Dryden y Pope por ejemplo.

Pero ya antes de la publicación de la obra de Anne Finch un grupo filosófico-literario de mujeres han ido desbrozando un camino árido y difícil, no sólo en lo que concierne a la escritura, sino en todo lo referente a la defensa de la mujer y sus olvidados derechos de igualdad, haciendo posible que ellas tengan la oportunidad de publicar poemas, ensayos, obras de teatro, relatos y todo tipo de escritura sin importar el género literario a la que pertenezca. Ya no es necesario que los textos remitan a cuestiones religiosas o familiares, pues Anne Finch y sus coetáneas propician un cierto

${ }^{1}$ Un solo ejemplo nos sirve para demostrar la afirmación: la antología de John Matthews Manley, English Poetry 1170-1892 (Boston-New York-Chicago-London, Ginn \& Company, 1907) no incluye a ninguna poetisa en el epígrafe denominado "Restoration", siendo Lady Winchilsea la única mujer que figura en el epígrafe "The Age of Classicism", con tres poemas suyos de los más conocidos: "The Petition for an Absolute Retreat", To the Nightingale" y "A Nocturnal Reverie"; antes de ella no se cita a ninguna poetisa y la siguiente será Anna Laetitia Barbauld, seleccionada en el apartado "Classicists and romanticists", de la que se incluye el poema "Life". 
estatus a las obras poéticas escritas por mujeres y algunas de ellas animan a las otras en el camino hacia el proceso liberador de la escritura: Mary Chudleigh y Elizabeth Thomas eran amigas y junto a Sarah Fyge Egerton y Elizabeth Singer Rowe pertenecen a círculos literarios de mujeres. De hecho, todas ellas, cada una en la medida de sus posibilidades, no hacen más que seguir el camino iniciado por Mary Astell, influenciadas por su ejemplo y versificando algunas de sus ideas.

El círculo de mujeres amigas que dan soporte intelectual, moral y financiero a Mary Astell, sin el cual no podría haber llevado a cabo su labor de apoyo, comprensión y ayuda a las mujeres necesitadas, desarrolla un estilo de vida independiente teniendo plena conciencia de ello, como ya había ocurrido con Aphra Behn y ocurrirá más tarde con Mary Wolstonecrasf; esta independencia se basaba en una premisas muy concretas y entre las que era fundamental la vida fuera del matrimonio con total independencia económica, lo que podría proporcionar el acceso a una educación equitativa con la del hombre y la creación de un 'espacio femenino' hasta entonces imposible de conseguir. Algunas historiadoras del movimiento feminista como Sara M. Evans resumen estas premisas en las siguientes:

social spaces, 2) role models of people breaking out of patterns of passivity, 3) an ideology than can explain the sources of expression, 4) a threat to the new-found sense of self that forces a confrontation whit the inherited cultural definition, 5) a communication of friendship network through which a new interpretation can spread, activating the insurgent consciousness into a social movement. ${ }^{2}$

Es digno de reseñar el hecho de que unas y otras suelan dedicar sus ensayos y poemas a las reinas 'Elizabeth and Anne Queen of Great Britain', lo que no tiene nada de extraño, ya que es similar a lo que ocurre en Francia: Mlle de Gournay dedicaba "Égalité des femmes" a "Queen Anne d'Autriche', la esposa de Luis XIII.

Alrededor de Mary Astell se agrupa un número de mujeres que han pasado a la historia literaria inglesa fundamentalmente por ese hecho: se trata normalmente de poetas, aunque también las hay que se dedican a la medicina o a la lengua; asimismo, se cita como miembro de pleno derecho de este grupo al clérigo y filósofo inglés John Norris, que mantuvo una importante correspondencia con Astell. Enumeremos ya a los componentes de este grupo: Lady Mary Chudleigh, Elizabeth Thomas, Judith Drake,

\footnotetext{
${ }^{2}$ Citado por Gerda Lerner en: The Creation of Feminist Consciousness: from the Middle Ages to Eighteen-seventy, Oxford University Press, 1993, pp. 232-233.
} 
Elizabeth Elstob, Lady Mary Wortley Montagu y John Norris. En este trabajo, tras mencionar los temas poéticos de que se ocuparon, analizaremos brevemente la figura de cada uno de los miembros integrantes, junto a un pequeño esbozo de su obra (normalmente un poema) que tenga relación con su pertenencia al círculo. ${ }^{3}$

\section{TEMAS POÉTICOS DEL CÍRCULO}

Dos son los temas fundamentales sobre los que van a versar la labor de los componentes del grupo reunido en torno a Mary Astell: la problemática religiosa y la defensa de los derechos de la mujer. Por los que respecta al primero, digamos que la religión es más una cuestión de experiencia personal que de dogma, aunque no se la debe disociar de la teología, del mismo modo un poema religioso está íntimamente ligado con las convicciones y creencias personales del autor, influenciado por las corrientes de ideas que intervienen en un momento preciso en la historia literaria, así como las fuerzas que operan en una época dada. Por muy personal, original e insólito que sea, el poema religioso se sitúa en una tradición literaria o en reacción contra ella. En la obra de algunos poetas religiosos como Jonh Donne, John Milton, Isaac Watts o Christopher Smart hay una fusión total entre la experiencia religiosa y la experiencia estética: el poema no es el relato de una experiencia religiosa, sino la propia experiencia vivida y transpuesta al plan estético. Así, la creación estética permite al poeta resolver un conflicto latente y liberarse de sus dudas.

A comienzos del XVIII, Swifft y sus contemporáneos no cesan de deplorar la tibieza de la fe y un gran número de aristócratas animan a sus sirvientes a que frecuenten la iglesia, con el fin claro de mantener en ellos el sentido de la disciplina y preservar en ellos la ley de la subordinación a los rangos. Añadamos a esto que a finales del XVII y a comienzos del XVIII se producen cambios profundos en la vida cotidiana debido a los descubrimientos científicos y a la filosofía de Locke. El clima racionalista en el cual se desarrolla el período no parece a priori favorable al desarrollo de la fe y a la eclosión de una poesía religiosa viva y sincera: la religión se siente amenazada por todas partes y su autoridad es puesta en cuestión. Otros factores vienen a contribuir al detrimento de la pérdida de la fe y la credibilidad de la religión como lo que hasta entonces había representado, entre ellos el culto a la razón, que explica el interés suscitado por el deísmo y el arrianismo. El 'latituditarismo'4 contiene en su seno a la vez la fuerza y

${ }^{3}$ Es evidente que algunas autoras, caso de Lady Mary Chudleigh o Lady Mary Wortley Montagu son mucho más conocidas que otras, lo que no supone merma alguna, ya que no debemos obviar a las menos conocidas.

${ }^{4}$ Así se denomina la actitud adoptada por algunos teólogos anglicanos en el s. XVII, que abogaban por una interpretación menos estricta o dogmática de la religión cristiana, lo que 
la debilidad de una fe racionalista, y la religión se convierte en una guía práctica que permite al hombre partir en busca de la verdad; es, en resumen, una religión desprovista de cualquier huella de misticismo.

Frente a este 'abandono' del culto de la religión en poesía continúa existiendo, al margen de las consideraciones filosóficas y de las controversias religiosas, una corriente de devoción profunda que se refleja sobre todo en la poesía. Se puede afirmar que críticos y poetas creen en la renovación de la poesía religiosas, de ahí que escritores tan diferentes como Thomas Ken, John Dennis, Sir Richard Blackmore, Joshep Addison, Isaac Watts, John Hughes, Aaron Hill o Edward Young estiman que los poetas deben sacar su inspiración de las Sagradas Escrituras, con el fin de volver a dotar a su 'arte' del poder y vigor del que carecen. La mayor parte de los poetas, al alba del siglo XVIII, componen poemas religiosos que publican en los diarios y volúmenes recopilatorios de ensayos o en las antologías de la época. No es que se inclinen ante una moda, sino que obedecen a una fuerza interior, a veces exigente y pura, que los arrastra fuera de los senderos familiares. Así, respondiendo a estos cánones, la poesía religiosa de la época presenta un doble aspecto que se plasma en las dos vertientes siguientes:

a) los poetas vuelven sus miradas hacia la religión natural, que sirve de soporte a la Revelación; extraen su inspiración de los 'físico-teólogos': la belleza y la armonía de la naturaleza son testimonio de la sabiduría y el poder del Creador.

b) bajo el impulso de Isaac Watts se desarrolla la poesía de un grupo de 'no-conformistas' que gravita a su alrededor y que escriben himnos dirigidos a un público popular, que contribuirán a la renovación de la fe.

En realidad no se produce una ruptura brutal entre el siglo XVII y el $\mathrm{XVIII}$, sobre todo en el período de transición que estamos analizando, atravesado por corrientes diversas en las que las nuevas tendencias se mezclan con las supervivencias del pasado. Varios poetas religiosos

permitiría continuar su adhesión a las formas externas de gobierno y culto anglicanos, manteniendo al mismo tiempo una cierta indiferencia o escepticismo sobre su validez absoluta. En este sentido la palabra inglesa latitude (latitud, libertad) guarda la significación original latina de amplio margen o espacio.

${ }^{5}$ El nombre es utilizado por vez primera por William Derham en su obra: Physico-Theology, or a Demonstration of the Being and Attributes of God from his Works of Creation. Being the Substance of XVI Sermon Preached... in the Year 1711 and 1712 (London, 1713). Los 'físicoteólogos' son denominados, asimismo, 'naturalistas', siendo los más relevantes: John Ray (1628-1705), Richard Bentley (1662-1742), William Derham (1657-1735) y William Hyde Wollaston (1766-1828), que propagan entre los lectores las nuevas ideas científicas, vulgarizadas luego por los (Lady Mary Chudleigh, Henry Needler, Addison y Sir Richard Blackmore escriben ensayos en prosa que ilustran la sabiduría de Dios en la Creación). Aclaremos que el tema central de la 'físico-teología' era la demostración de la relación entre la perfección del mundo y el perfecto ensamblaje de sus partes con la existencia de Dios. 
prolongan en el XVIII los modos de pensamiento y expresión que pertenecen a una época anterior: Simon Patrick (1626-1707) ${ }^{6}$, Thomas Ken $(1637-1710)^{7}$, John Norris (1657-1711) -del que nos ocuparemos ahora al ser el único hombre relacionado con el grupo de Astell, a la que influencia con su pensamiento-, Nahum Tate $(1652-1715)^{8}$, Lady Mary Chudleigh (1656-1710) -a la que también trataremos de modo más detallado-, Lady Winchilsea $(1661-1720)^{9}$, Samuel Wesley $(1662-1735)^{10}$, John Pomfret $(1667-1702)^{11}$ y John Hughes (1677-1720) ${ }^{12}$. Dada la importancia de Norris en el pensamiento del círculo, fuertemente impregnado de su filosofía y manera de vivir el cristianismo, veamos primero su figura para analizar luego las de Mary Astell y las otras componentes del círculo.

\subsection{John Norris (1657-1711)}

Clérigo inglés y filósofo, fue Rector de Bemerton y antiguo miembro del All-Souls' College, así como traductor y comentarista de Platón y seguidor del francés Malebranche. Su obra principal es An Essay towards the Theory of the Ideal or Intelligible World (1701-4) en cuya segunda parte, sobre el entendimiento humano, critica el empirismo de Locke en su Essay on Human Understanding. ${ }^{13}$ Su importancia como filósofo estriba en elaborar una versión del ocasionalismo basada en la distinción platónica entre el mundo natural o sensible y el ideal o inteligible: el segundo, al ser el fundamento del primero y contenerlo eminentemente, es más cierto y evidente que él. El mundo ideal debe ser, por tanto, el ámbito del

${ }^{6}$ Predicador conocido por sus obras en prosa, del que se publica tras su muerte Poems upon Divine and Moral Subjects (1719).

${ }^{7}$ Uno de los siete obispos que fueron encarcelados en la Torre de Londres en 1688 por no jurar fidelidad a Guillermo III y a su esposa la reina María, abjurando de su promesa a Jacobo II; está considerado como uno de los padres de la moderna 'hymnology'.

${ }^{8}$ Irlandés e hijo de un pastor protestante, poeta laureado en 1692, en 1696 publica en colaboración con Nicholas Brady: A New Version of the Psalms of David, así como Miscellanea Sacra: Or Poems on Divine and Moral Subjects.

${ }^{9}$ Sólo compuso un pequeño número de poemas religiosos, teñidos todos de una fe ferviente y sincera, muy parecida a la mostrada por Thomas Ken., destacando más por sus alusiones al 'spleen'.

${ }^{10}$ Padre del líder religioso John Wesley (1703-1791), disidente convertido en pastor de la Iglesia anglicana, publica en 1693 un poema épico en diez cantos sobre un tema sagrado: The Life of our Blessed Lord and Saviour Jesus Christ, en el que imita a Milton y Cowley.

${ }_{11}$ Pastor de Malden que comparte con Wesley su admiración por Cowley y su gusto por lo sublime. En su obra Upon the Divine Attributes alaba la unidad, poder, sabiduría, providencia, omnipresencia, inmutabilidad, justicia y bondad de Dios.

12 Dramaturgo, poeta, crítico y traductor que gozó de un cierto renombre en los círculos literarios de su época, era un firme defensor de la creencia en los orígenes sagrados de la poesía.

${ }_{13}$ Para la controversia con Locke, véase la obra de éste traducida al castellano por Ángel M. Lorenzo: La conducta del entendimiento y otros ensayos póstumos, Barcelona, Anthropos, 1992. 
conocimiento, pues en él se encuentran todas las ideas y verdades eternas, gracias a las cuales podemos contemplar todo lo demás. Pero tales ideas y verdades no proceden de nuestras propias almas, sino de Dios, en el cual las vemos. Por consiguiente, todo verdadero conocimiento se basa en una contemplación de las ideas divinas. El pensador representa una fuerza intelectual muy activa a comienzos del XVIII y el volumen de ensayos y poemas que publica en $1687^{14}$ llegará a su décima edición en 1730 y ejercerá una influencia considerable en escritores tan diversos como Lady Chudleigh, John Hughes, Isaac Watts, Elizabeth Singer Rowe o Henry Needler. En su correspondencia con Henry More discute de problemas metafísicos.

Entre sus obras son dignas de mención A Collection of Miscellanies (1687) y An Account of Reason and Faith (1697). En 1690 escribe Reflections upon the Conduct of Human Life with reference to the Study of Learning and Knowledge, in a letter to an excellent Lady, replicando ésta Lady Masham- de modo anónimo en Occasional Thoughts in Reference to a Virtuous or Christian Life (1691). En la actualidad es conocido por seguir e incorporar a sus teorías las ideas de Platón, San Agustín, Henry More y Malebranche, pudiendo definirse su pensamiento como una unión entre los platónicos de Cambridge y Shaftesbury. Veamos uno de sus poemas representativos:

\section{TO SLEEP}

$$
\text { I }
$$

Break off thy slumber, gentle God

And hither bring thy charming rod;

The rod that weeping eyes does dole

And gives to melancholy hearts repose;

With that my temples stroke, and let me be

Held by thy soft captivity.

But do nor all my senses bind,

Nor setter up too close my mind:

Let mimick fancy wake, and freely rove,

And bring th' idea of the Saint I love.

II

Her lovely image has been brought

So often to my waking thought,

That 'tis at length worn out and dead,

14 A Collection of Miscellanies: Consisting of Poems, Essays, Discourses and Letters, Occasionally written by John Norris, $6^{\text {th }}$ ed.London: Printed by W. Bowyer, S. Manship, 1717 (1687). 
And with its fair original is fled.

Or else my working over-thoughtful mind

With much intention is made blind;

Like those who look on objects bright

So long, till they quite lose their sight.

Ah cruel fates! is't nor enough for you

To take my Saint, but I must lose her image too?

III

Thee, gentle charmer, I implore

This my lost treasure to restore;

Thy magick virtues all apply,

Set up again my bankrupt memory.

Search every cell and corner of my brain,

And bring my fugitive again.

To thy dark cave thy self betake

And 'mong thy dreams enquiry make;

Summon the best ideas to appear

And bring that form which most resembles her.

\section{IV}

But if in all thy store there be

None (as I fear) so fair as she,

Then let thy painter fancy limn

Her form anew, and fend it by a dream.

Thou can'st him all her lively features tell,

For sore I think thou knew'st her well.

But if description won't suffice

For him to draw a piece so nice,

Then let him to my breast and heart repair.

For sure her image is nor worn out there.

\section{AL SUEÑO}

$$
\text { I }
$$

Interrumpe tu sueño, Dios amado,

y ofrécenos tu misteriosa cruz;

la cruz que compungidos ojos lloran y al alma triste el reposo concédele; golpea esto mis sienes, pero déjame ser un cautivo en tus dulces prisiones.

Pero no amarres todos mis sentidos,

ni mi mente amordaces en exceso:

deja a la fantasía vagar libre

y que a la mente me traiga a mi Santa.

Hikma 9 (2010), 87-116 


\section{II}

Su amada imagen ha sido traída a mi pensamiento tan a menudo, que al fin se desvanece y se apaga, y con su original desaparece.

O si no mi mente sobrecargada de tanta intención queda ya cegada; como quien mira un objeto brillante tan largo tiempo que pierde su vista. ¡Oh cruel hado! No es ya suficiente robarme la santa, mas debo aún perder su imagen?

\section{III}

A ti, amado encantador, te imploro porque mi oculto tesoro devuelvas, tus mágicas virtudes pues aplica, restablece mi memoria quebrada. Cada rincón de mi mente escudriña y tráeme de nuevo a mi fugitiva.

Retírate pues a tu oscura cueva y entre sus sueños haz indagaciones; convoca allí a las mejores ideas y trae la forma que más se parezca.

$$
\text { IV }
$$

Pero si en todo tu almacén no hubiere una (eso temo) tan bella como ella, deja entonces al pintor retratar su forma de nuevo, que valga un sueño. No puedes contarle todos sus rasgos Seguro que tú la conoces muy bien.

Pero si las descripción no es bastante para pintar tan hermoso modelo, déjalo que a mi pecho y alma venga. Seguro que su imagen aún pervive.

\section{MARY ASTELL (1666-1731)}

Considerada como la primera feminista inglesa y mujer de reconocido prestigio por sus creencias y desarrollo de los conceptos alusivos a la educación de las mujeres, Mary nace en Newcastle en una familia de tres hermanos de clase media. Recibe una amplia educación sobre filosofía, matemáticas, teología, política, historia y literatura y vivirá una juventud gozando del placer de la lectura. A los veinte años se traslada a Londres, donde forma un círculo de mujeres ansiosas de conocimientos. Nuestra autora estaba convencida que el desarrollo cultural de las mujeres era lo 
único que les podía garantizar la libertad de elección: debían convertirse en seres autosuficientes, tanto emocional como intelectualmente, para poder ser ellas mismas. El deseo y el amor al saber irá siempre unido a la felicidad y al goce del conocimiento, teoría expresada en su obra: Propuesta formal dedicada a las damas para el mejoramiento de sus verdaderos y más grandes intereses (1 ${ }^{a}$. parte aparecida en 1694 y la $2^{a}$. en 1697). En 1700 publica Reflexiones sobre el matrimonio, donde con humor e ironía pone en evidencia las costumbres de la época, que humillaban y sometían a las mujeres a un matrimonio, que Mary definía como una institución tiránica. Ella aconseja a otras mujeres a no aceptar un matrimonio no deseado, que meditaran sus propias decisiones, que era preferible vivir sola o en relación con otras mujeres. Hacia el final de su vida se dedicará a dirigir una Escuela de Caridad para hijas de militares retirados del Hospital de Chelsea, que existió hasta 1862; veamos todo con más detalle.

Su padre era un hombre de ideas conservadoras y monárquico que gestionaba una empresa de carbón. Como mujer, Mary no recibió ninguna educación formal por parte paterna, muriendo éste teniendo ella doce años y yéndose a vivir entonces con su tío, un ex-clérigo (cuya implicación con el alcoholismo ocasionó su suspensión de la Iglesia de Inglaterra) hasta 1688. En una época en que la mayoría de las mujeres eran analfabetas, ella recibió una educación que comprendía estudios de filosofía, matemáticas y algunas lenguas modernas; por su obra se puede deducir que poseía además conocimientos de teología, política, historia y literatura clásica. Cuando tiene alrededor de veinte años, decide trasladarse a Londres con la intención de permanecer soltera y dedicada a la literatura, siendo muy consciente tanto de las limitaciones que la sociedad de su tiempo imponía a las mujeres como de la fuerza de sus propios deseos: los de un alma 'nacida para más', que aspira a la grandeza. En la capital se instala en el barrio de Chelsea, donde poco a poco se formará en torno a ella un círculo de mujeres, que serán a lo largo de los años sus compañeras más íntimas y su principal apoyo, tanto económico como emocional: Lady Elizabeth Montague (a quien dedicó la edición de 1694 de su Proposal to the Ladies), Lady Catherine Jones (a quien John Norris, a petición suya, dedicaría Letters Concerning the Love of God, between the author of the 'Proposal to the Ladies' and Mr John Norris, en 1695), Elisabeth Hasting, Ann Coventry, Lady Mary Chudleigh, Elizabeth Thomas, Judith Drake, Elizabeth Elstob, etc., que la ayudan en el desarrollo y en la publicación de sus trabajos. ${ }^{15}$

Se trataba de mujeres aristócratas que contaban con abundantes ingresos propios, pero que habían optado por llevar una vida semejante a la

${ }^{15}$ Estuvo también en contacto con el Arzobispo de Canterbury, William Sancroft (1678-1690) conocido por sus obras de beneficencia, que también la ayudará financieramente y presentaría su obra para que fuera editada. 
de Mary: habían decidido permanecer solteras o bien se habían negado a casarse de nuevo al quedarse viudas. Compartían todo tipo de intereses e inquietudes, desde libros hasta remedios caseros, pero todas reconocían la autoridad de Mary, siendo mujeres que mantenían una red de relaciones de solidaridad con otras menos favorecidas económica y socialmente, (ayudaban a viudas sin hogar, enseñaban a sus criadas a leer y a escribir o proporcionaban instrucción escolar a las niñas de su familia), compartiendo todas ellas las mismas ideas sobre la educación de las mujeres y apoyando a Mary cuando, hacia el final de su vida, habiendo dejado de escribir, se dedicó a dirigir una Escuela de Caridad para hijas de militares retirados del Hospital de Chelsea, que existió hasta 1862. Fue ésta la única realización educativa que Mary Astell pudo llevar a la práctica, ya que su Proposal no llegó nunca a materializarse.

A los sesenta años Mary Astell se retira a casa de su amiga Catherine Jones, donde permanecerá hasta su muerte en 1731. Morirá a causa de un cáncer de mama y en sus últimos momentos rechaza ver a sus conocidos, recluyéndose en una sala para pensar solamente en Dios. Actualmente es reconocida por su capacidad para debatir libremente con todos sus intelectuales de su época. La teoría del dualismo de Descartes, mente y cuerpo, permitió a Astell promover la idea de que tanto mujeres como hombres fueron bendecidos con la razón, y que por lo tanto ellos no deberían ser tratados con más privilegios. A Serious Proposal to the Ladies for the Advancement of their True and Greatest Interest (London, 1694, $\left.1697^{16}, 1701\right)$, Letters Concerning the Love of God, between the author of the 'Proposal to the Ladies' and Mr John Norris (London, 1695) y Some Reflections upon Marriage (London, 1700) son ensayos impregnados de filosofía de la que es considerada por muchos como la primera feminista, con unas propuestas avanzadísimas para su tiempo y de una modernidad que sorprende aún hoy, lo que puede que contribuyera a desatar críticas tan acerbas en torno a ella por parte de escritores de su época. Veamos el poema "Ambition", compuesto con tan sólo 18 años, en el cual aporta su opinión argumentada en el debate "Who falsely say that women have no soul'. El poema está incluido en la antología The Ladies Library (1714) de Richard Steele ${ }^{17}$ y fue satirizado en el periódico The Tartle por Jonathan

${ }^{16}$ A Serious Proposal to the Ladies, Part II, (London, 1697), es decir la segunda parte de su ensayo, está editada por Patricia Springborg, con introducción y notas (London: Pickering \& Chatto, 1997). Existe traducción castellana en: Margaret L. King, Mujeres renacentistas. La búsqueda de un espacio, Madrid, Alianza Universidad, 1993, revisada y completada por Caroline Wilson.

${ }^{17}$ Los capítulos o partes de que constaba la obra hacían referencia al papel de la mujer en la familia con títulos como "Wit and Delicacy", "Dress, "Chastity", Modesty", "Envy", "Censure", Ignorance", "The Daughter", "The Wife", "The Mather", The Widow", "The Mistress", etc. 
Switf; su temática puede ser representativa de la de todas las escritoras de su época, asaltadas por la ambición y el deseo de escribir y reflejar en sus obras sus deseos, inquietudes y anhelos:

AMBITION

(Mar 30. 1684)

I

What's this that with such vigor fills my breast?

Like the first mover finds no rest,

And with its force does all things draw,

Makes all submit to its imperial law!

Sure 'tis a spark 'bove what Prometheus stole,

Kindled by a heavenly coal,

Their sophistry I can control,

Who falsely say that women have no soul.

II

Vile greatness! I disdain to bow to thee,

Thou art below even lowly me,

I would no fame, no titles have,

And no more land than what will make a grave.

I scorn to weep for worlds, may I but reign

And empire o'er my self obtain,

In Caesar's throne l'd not sit down,

Nor would I Stoop for Alexander's crown.

III

Let me obscured be, and never known.

Or pointed at about the town,

Short-winded fame shall not transmit

My name, that the next age may censure it:

If I write sense no matter what they say,

Whether they call it dull, or pay

A reverence such as a Virgil claims.

Their breath's infectious, I have higher aims.

IV

Mean-pitited men! That bait at honor, praise,

A wreath of laurel or of bays,

How short's their immortality!

But oh a ceown of glory ne'er will die!

This I'm ambitious of, no pains will spare

To have a higher mansion there,

There all are kings, here let me be,

Great $O$ my God, great in humility. 


\section{AMBICIÓN}

(30 de marzo de 1684)

$$
\text { I }
$$

¿Qué es lo que con tal vigor rebosa en mi pecho? ¡Como primer impulso que no encuentra reposo y con su fuerza arrastra todas las otras cosas,

y hace rendirse a todo a su ley imperial!

Seguro que es la chispa que Prometeo robó que encendida por el celestial carbón, el sofisma que encierra puedo yo descifrarlo, que en falsedad defiende que la mujer no ha alma. II

¡Vil grandeza!, rechazo postrarme ante ti, tu eres muy pequeña con respecto a mí, no tendré fama alguna, ni títulos tampoco, y tampoco más tierra que la que habrá en la tumba. No lloro por el mundo, pero puedo reinar y lograr un imperio con mis propias virtudes: en el trono de César yo no me sentaría, ni me inclinaría ante la tiara de Alejandro. III

Déjame en la penumbra y seguir siendo ignota. Cuando se es señalada por toda la ciudad, la fama de alas cortas nunca transmitirá mi nombre, que en la próxima edad censurarán: si escribo con sentido no importa lo que digan, si lo consideraran pálido, o bien lo alaban del mismo modo que Virgilio defendiera:

su aliento es infeccioso, yo soy de miras altas. IV

¡Qué hombres tan piadosos!, se burlan del honor y alaban la corona de laurel o de mirto, ¡cuán corta se revela vuestra inmortalidad!

¡Mas corona de Gloria jamás podrá morir!

Soy ambiciosa en esto, no dejará el dolor de poseer allí una mansión sublime do estén todos los reyes; déjame estar aquí,

¡oh, Tú, mi gran Dios, grande siempre en la humildad!

\section{1. Lady Mary Chudleigh (1656-1710)}

Nacida en Winslade (Devon) en su infancia es destacable la ausencia de una instrucción formal y su vertiente religiosa anglicana, siendo meritorio su hábito e inclinación por el deleite de la lectura sobre temas diversos que van desde la teología a la ciencia y a la filosofía. En Devon, contrae matrimonio a los 17 años con Sir George Chudleigh, de Ashton, y parece 
que tuvieron tres hijos: Eliza Maria, George y Thomas. Algunos estudiosos ingleses han señalado la mirada negativa de la poetisa hacia el matrimonio (a tenor de las referencias de Mary al vínculo conyugal como una trampa), señalando el despotismo de su marido; sin embargo, la crítica está dividida ya que hay quienes aducen una experiencia feliz y expresan como ejemplo los trabajos feministas que Sir George le permitió publicar y que él mismo siguió reeditando tras la muerte de ella en 1710.

Lady Mary participa de las dos vertientes poéticas del grupo: la religiosa y la defensa de los derechos de la mujer. En la primera acepta el cristianismo tolerante y razonable de Thomas Burnet y su Telluris Teoria Sacra (1681), de Edgard Stillingfleet, conocido como 'the beauty of holiness' y de Archbishop John Tillotson y de sus 'latitudinarios'; pero ante todo está influenciada por el platonismo de John Norris, al cual añade una coloración idealista y sentimental. En Poems on Several occasions (1703), exalta los encantos de la soledad y del 'retirement' que incitan a la lectura y a la meditación -las dos ocupaciones favoritas de Lady Mary-. Confiesa la autora un culto particular a Platón y aspira a la 'luz eterna'. En el poema "The Elevation" la escritora desea despojarse, lo más pronto posible, de la envoltura carnal que le impide saborear las alegrías más puras del espíritu:

Souls without Spot, till Flesh they wear,

Which their pure Substance stains:

While they th'uneasie Burthen bear,

They're never free from Pains. ${ }^{18}$

"The Offering" está también teñido de platonismo:

To Love I will my self resign;

But it shall be to Love Divine

That o'er me ever shall preside,

Shall ev'ry Word, and ev'ry Action guide. ${ }^{19}$

En el poema ya citado "To Amystrea", la escritora nos presenta una visión sorprendente del cielo, al asociar confusamente una forma de cristianismo sentimental, Platón y la ópera; propone a Amystrea (Mary Astell) que rechace las 'fruslerías brillantes' que atraen a su sexo y se consagre a los placeres intelectuales. Le sugiere, asimismo, que contemple las 'estancias oscuras' de los muertos, luego que abandone estas 'sombras siniestras, para 'dar una larga caminata' en el reino de los cielos y admirar 'la ópera del amor eterno':

18 "The Elevation", Poems on Several Occasions, London, 1703, p. 34.

${ }^{19}$ Ibidem, p. 103. 
View the dark Mansions of the mighty Dead,

And all their close Recesses see;

Then from those awful Shades retire,

And take a Tour above,

And there, the shining Scenes admire,

The Opera of eternal Love;

Pero la mayor parte de su obra trata sobre temas feministas y se publica en el último tramo de su vida en forma de un libro de poemas y dos libros de ensayos, y goza de tal predicamento que algunos libros cuentan hasta cuatro ediciones durante la vida de la autora. Los temas principales de su poesía son las relaciones humanas destacando su temática capital sobre el feminismo: en efecto, muchos poemas de Chudleigh recrean los placeres de la amistad entre mujeres y apuntan que dicha amistad está basada en valores morales compartidos y en fines intelectuales comunes.

Su obra es una muestra de las guerras 'de género' que comenzaron con antelación en la cultura inglesa; así, parte del contenido de sus libros consiste en una respuesta al sermón nupcial que publica el ministro John Sprint en 1700 titulado The Bride-Woman's Counselor. Al año siguiente la luz de la imprenta alumbra The Ladies Defence: or the Bride-Woman's Counsellor answered: A Poem. In a Dialogue Between Sir John Brute, Sir William Loveall, Melissa, and a Parson. La escritora basa sus argumentos en la aureola de ignorancia que los hombres le otorgan al sexo femenino y se impone demostrar que las mujeres también poseen intereses culturales e intelectuales, los cuales son coartados y limitados por la sociedad. Por otra parte, reclama un lugar más justo e increpa al varón por quejarse de la debilidad femenina, cuando es precisamente la voluntad del hombre la que la 'modela' de este modo. Su obra clama por el aumento de la educación en la población femenina y pone de relieve la sumisión y la obediencia servil que la mujer profesa al varón.

Los trabajos de Mary Chudleigh aparecen incluidos en varias antologías de los siglos siguientes y los poemas sobre las relaciones humanas y sobre la defensa de la mujer han cautivado a lectores de ambos sexos, aunque su nombre no haya merecido la atención de ser bien estudiado y analizado en algunos diccionarios literarios. Son temas sobresalientes en su legado las críticas a la iglesia por expandir ideas perniciosas sobre la mujer, las obligaciones tradicionales de la esposa, su obediencia callada, la tolerancia de las mujeres, los abusos a varios niveles a los que están sometidas, así como la restricción educativa al varón o la consabida negativa hacia la educación de la mujer y el desequilibrado papel 
en la estructura familiar de la mujer respecto del hombre. Veamos su poema más conocido, alusivo a la temática del matrimonio: 
TO THE LADIES

WIFE and servant are the same,

But only differ in the name:

For when that fatal knot is ty'd,

Which nothing, nothing can divide:

When she the word obey has said,

And man by law supreme has made,

Then all that's kind is laid aside,

And nothing left but state and pride:

Fierce as an eastern prince he grows,

And all his innate rigour shows:

Then but to look, to laugh, or speak,

Will the nuptial contract break.

Like mutes, she signs alone must make,

And never any freedom take:

But still be govern'd by a nod,

And fear her husband as a God:

Him still must serve, him still obey,

And nothing act, and nothing say,

But what her haughty lord thinks fit,

Who with the power, has all the wit.

Then shun, oh! shun that wretched state,

And all the fawning flatt'rers hate:

Value yourselves, and men despise:

You must be proud, if you'll be wise.

\section{A LAS DAMAS}

Esposa y servidora son una misma cosa, pues solo se distinguen en tener otro nombre: desde el fatal momento en que el nudo se ata, ya ni nadie ni nada separarlos podrán: cuando ella ha pronunciado el verbo obedecer. y por la ley suprema en marido el hombre se convierte, el resto pasa a ser secundario, y nada queda de antes salvo estatus y orgullo, que feroz va aumentando cual príncipe oriental y todos sus rigores congénitos enseña: 


\begin{abstract}
desde entonces mirar, reírse o hablar, quedará roto por el contrato nupcial. Cual los mudos, sola ella, debe gesticular y no tomarse nunca ninguna libertad: debe dejarse, incluso, gobernar con un gesto y temer a su esposo como si fuera un Dios: a él debe servir, a él debe obedecer, y no actuar por su cuenta, ni sugerir siquiera, mas lo que crea oportuno su altanero señor, a quién se le infundió el poder y el ingenio. Así pues evitad, ese horrible estado, y todas detestad adulación y halagos: valoraos vosotras, despreciad a los hombres: debéis mostraros dignas, si queréis ser instruidas.
\end{abstract}

\title{
2. 2. Elizabeth Thomas (1675-1730)
}

Nacida en Londres, era hija única de Elizabeth Osborne y del abogado Emmanuel Thomas, que murió cuando ella era aún niña, por lo que su familia debió pasar serias penurias económicas. Como era normal en su época en familias de buena posición social recibió educación con tutores en su propio domicilio. Llegó a ser muy culta en letras, destacando en latín y francés. Como burguesa venida a menos, dependió en parte del patronazgo de terceros, y tuvo la fortuna de formar parte del un ilustre círculo literario y artístico de Mary Astell. Tuvo la inmensa suerte de que Dryden leyera dos de sus poemas inéditos poco antes de la muerte del célebre poeta, quien los reseñó de esta forma: "your Verses were, I thought, too good to be a Woman's" ("sus versos eran, pensé yo, demasiado buenos para provenir de una mujer") y la comparó con la ya famosa Katherine Philips, además de imponerle su seudónimo de 'Corinna'.

Su primer publicación conocida fue una elegía titulada "To the Memory of the Truly Honoured John Dryden, Esq", de forma anónima en la antología dedicada al poeta fallecido y titulada Luctus Britannici (1700).

Durante dieciséis años estuvo comprometida con Richard Gwinnett (1675-1717) aunque la situación económica de ambos no aconsejó la celebración de su unión hasta 1716, en cuya fecha Elizabeth aplazó el matrimonio con el fin de atender a su madre, gravemente enferma. Gwinnet falleció al año siguiente, y aunque legó una herencia a Elizabeth, la familia de aquél recurrió legalmente el testamento y, tras los litigios procedentes, Elizabeth Thomas no pudo siquiera hacer frente a las onerosas costas del proceso. Durante la larga época de su compromiso ambos habían mantenido una abultada correspondencia, gran parte de la cual fue publicada en Pylades and Corinna (1731-1732) y en The Honourable Lovers (1732). 
Elizabeth Thomas asistió como miembro asiduo y de notable reputación a los círculos literarios tanto de Londres como de Bath. En su práctica literaria experimentó con muy diversos tipos de géneros y formas poéticas que van desde la lírica al panegírico pasando por la poesía bucólica, la polémica, las meditaciones religiosas o la sátira. Buena parte de su poesía está dedicada a temas femeninos, en particular al derecho de las mujeres a la educación, puesto que a las mujeres en su época "se nos negaba aún el cultivo de la mente". Su obra circuló al principio en forma manuscrita pero, acuciada por la necesidad económica, publicó anónimamente Miscellany Poems on Several Subjects en 1722, dejando para más tarde la publicación con su rúbrica.

Poco antes su amigo Henry Cromwell le había regalado algunas cartas que éste había recibido del poeta Alexander Pope, ya por entonces famoso en todo el reino y Thomas, en apuros económicos, se las vendió a Edmund Curll en 1726. Tan innoble acto causó en Pope una enorme consternación, lanzando a Thomas acres dardos satíricos en su obra The Dunciad, a la que se dirige con el nombre de "la Corinna de Curll" (II, 66). Una venganza de la poeta aunque de menor entidad se la atribuyó el propio Pope -la publicación de Codrus, or, 'The Dunciad' Dissected (1728)- aunque para entonces Elizabeth había sido encarcelada por deudas. Su reputación se vio gravemente afectada al airearse tales hechos, llegando incluso a ser objeto de rumores infundados que la acusaban de haber sido la amante del citado HenryCromwell.

Aunque asociada con Curll en las publicaciones durante esa década de 1720 , finalmente no pudo hacer frente a sus deudas y fue a dar con sus huesos a la prisión de Fleet en 1727 condenada a cumplir una sentencia de tres años. Nunca disfrutó de buena salud, pero la cárcel fue un destino cruel para su organismo, muriendo al año de haber recobrado la libertad, en la soledad de una pensión mísera. Fue enterrada en el viejo camposanto anejo a la iglesia de St. Bride, en Fleet Street. Veamos un poema dirigido a Mary Astell:

\section{To Almystrea [Mary AstelL], ON Her Divine Works}

Hail, happy virgin! Of celestial race,

Adorned with wisdom, and replete with grace!

By contemplation you ascend above,

And fill your breast with true seraphic love.

And when you from that sacred mount descend,

You give us rules our moral to amend:

Those pious maxims you yourself apply,

And make the universe your family. 
No more, Oh Spain! Thy Saint Theresa boast, Here's one outshines her on the British coast; Direct as well, and regulates her love,

But in that sphere with greater force doth move. Whose soul, like hers, viewed its almighty end! And to that centre all its motions tend: Like her, she glorious monuments doth raise, Beyond male envy! Or a female praise!

Too long! Indeed, has been our sex decried, And ridiculed by men's malignant pride; Who, fearing of a just return, forbore, And made it criminal to teach us more. That women had no souls was their pretence, And women's spelling passed foe women's sense. When you, most generous heroine! Stood forth, And showed your sex's aptitude and worth. Were it no more, yet you, bright maid, alone Might for a world of vanity atone!

Redeem the coming age! And set us free From the false brand of incapacity.

\section{A ALMISTREA [MARY ASTELL], POR SUS DIVINAS OBRAS}

¡Salve, oh joven virgen! ¡De raza celestial, de sapiencia adornada y de gracia repleta! Por la contemplación hasta el cielo te elevas y en tu pecho atesoras un gran amor seráfico. Y cuando tú desciendas de ese sagrado monte, otórganos las reglas que enmienden nuestra vida: esas máximas pías tú misma las aplicas, de todo el universo haciendo tu familia.

¡Basta ya, oh España!, de Teresa orgullosa, aquí hay quien la supera en las costas británicas; igualmente directa, su amor somete a reglas, pero en esas esferas con más fuerza se mueve. ¡Qué alma cual la suya ve tan alto objetivo! Apuntando su flecha directa a esa diana: iigual que ella, eleva gloriosos monumentos, sin masculina envidia ni femenina loa!

Cuán largo tiempo ha sido odiado nuestro sexo y ridiculizado por arrogantes hombres;

quienes, ante una justa respuesta, se abstuvieron, 
107

declarando delito que aprendiéramos más.

Que carecía de alma la mujer pretendían,

mas de ésta la sapiencia toda insidia vencía.

Tu te pusiste en pie, igenerosa heroína!,

y mostraste cuán apto y valioso es tu sexo.

\section{3. Elizabeth Elstob (1683-1756)}

La denominada "Saxon Nymph" es actualmente considerada una de las primeras feministas inglesas junto a Mary Astell y una de las mujeres más doctas de la cultura inglesa: llegó a dominar ocho lenguas, siendo pionera en los estudios de anglosajón. Descendía de la antigua y prestigiosa familia de los Elstob, o Foxton, en la diócesis de Durham. Su padre Mr. Ralph Elstob, fallecido en 1688, era un comerciante de Newcastle casado con Jane Hall, hija de otro comerciante. Elizabeth adquirió los rudimentos de su extraordinaria educación por su madre, aunque a los ocho años se quedara sin padres. No obstante, sus tutores siguieron la labor de educarla intelectualmente, llegando incluso a matricularse en Oxford, donde llegó a ser respetada y estimada por varios de sus profesores. Aunque no se sabe a ciencia cierta lo más probable es que acompañara a su hermano William a Londres en sus investigaciones sobre la Antiguedad. Con ocasión de una homilía de su hermano en el día de St. Gregory's ("English-Saxon Homily on the Nativity of St Gregory") que apareció en 1709, ella le añadió la traducción inglesa en la cual escribiría un prólogo respondiendo a las objeciones que se hacían a las mujeres instruidas. Su siguiente publicación fue la traducción de un ensayo de Madeleine de Scudéry: "Essay upon Glory". Los dos trabajos fueron dedicados a la reina Anne, elogiada en dos prólogos feministas. La traducción sobre la escritora francesa está basada en el premio de elocuencia concedido por vez primera por la "Académie Française" a la autora por su ensayo "Discours de la Gloire" ${ }^{20}$, en el cual la escritora adopta criterios tradicionales y religiosos; se pensó, incluso en elegirla académica, aunque en lugar de hacerlo en París lo hicieron en los Ricovrati de Padua ${ }^{21}$.

${ }^{20}$ Conocido también como "Discours sur la Gloire", Paris, Pierre Le Petit, 1671

21 La Accademia dei Ricovrati fue fundada en Padua, en 1559, por iniciativa del noble veneciano el abad Federico Cornaro; a su fundación asistieron 25 personas distinguidas, entre ellas Galileo. El nombre proviene de 'Ricovrati' (protegidos, resguardados) de la imagen de una caverna abierta por los dos extremos y resguardada por un olivo con la divisa de Boecio: Bipatens animis asylum (un santuario del espíritu abierto por los dos lados).

A finales del siglo XVII la Academia se plantea la disyuntiva de recibir en su seno a mujeres y entre ellas a aquellas que obtienen diplomas universitarios o similares: Elena Cornaro Piscopia en 1679, Anne Dacier en 1679, Madeleine de Scudéry en 1685 y Maria Selvaggia Borghini en 1689. De 25 admitidas entre los siglos XVII y XVIII, únicamente cuatro fueron italianas, siendo 
Desde 1702, Elizabeth formó parte del círculo de mujeres reunida en torno a Mary Astell, que la ayudó a encontrar suscritores para su obra Rudiments of Grammar for the English-Saxon Tongue (London, Bowyer and King,1715), el primero de los trabajos escrito en inglés sobre anglosajón. El prólogo: "An Apology for the Study of Northern Antiquities" discrepaba de la opinión de Jonathan Swift y parece que lo llevó a revisar sus puntos de vista. Esta primera gramática debe también mucho al apoyo emocional y material de su hermano, que tuvo gran importancia en su formación ${ }^{22}$; posteriormente, al morir éste, se vio obligada a ganarse la vida como maestra e institutriz sin lograr publicar sus otras traducciones ni continuar sus investigaciones a pesar de que algunos amigos le consiguieron un puesto de institutriz en casa de la duquesa de Portland, recibiendo también ayuda por parte del obispo Smalridge y Hestor Mulso Chapone. John Nichols reeditó parte de su correspondencia. A su muerte fue denominada "the "female student" de Oxford University.

Por lo que concierne a la obra de Elizabeth Elstob, conviene que nos detengamos brevemente en la situación de la lengua inglesa en la época en que escribe la autora. La elegancia, la claridad y la fluidez del estilo aliadas a una cierta variedad son, a finales del XVII y comienzos del XVIII, las cualidades más apreciadas por los críticos. Sin embargo, hay reticencias hacia un tipo de poesía que peca quizá de exceso de refinamiento, lo que lleva a una cierta monotonía. Aclaremos que en realidad el problema parte del hecho de que durante el siglo XVII el racionalismo científico arrastra -según la denominación de T. S. Elliot que tanta repercusión ha tenido en el mundo de la crítica- una "disociación de la sensibilidad" ${ }^{2}$. Ya no se encuentra en los

el resto francesas que no tenían derecho a asistir las sesiones; las asistentes sólo eran honorarias y no votaban ni ocupaban puestos administrativos.

Por lo que se refiere a la cuestión de la igualdad entre los sexos, se incluían en los debates problemas que afectaban a la denominada "cuestión de las mujeres", con temas del estilo siguiente:

- ¿Sería preferible excluir a las mujeres del gobierno, tal como hacían los romanos, o admitirlas, tal como hacían los griegos?

- ¿Bajo el reinado de una mujer, debería ésta consagrarse a las armas o a las letras?

- ¿Los hombres, por su bien, deberían o no enamorarse?

${ }^{22}$ William era diez años mayor que ella y había recibido una esmerada educación gramatical, primero en Newcastle y luego en Eton antes de ser admitido en el "Catherine Hall" de , Cambridge y posteriormente en el "Queen Collage" de Oxford, donde su gran reputación lo llevó a ser elegido en 1696 "fellow" (miembro de la Junta de Gobierno)

${ }^{23}$ Eliot pensaba que en algún momento la sensibilidad se disoció del lenguaje, de pensamiento, y siguiéndole la pista piensa que contribuyeron a ello enormemente poetas como Milton y Dryden. En el tiempo en que tal disociación no existía. Eliot trataba de hallar una sensibilidad poética "no disociada" y la encontró en John Donne, al diseccionar la Antología de poetas metafísicos del XVII que Herbert Grierson había publicado en 1921 (Herbert J. C. Grierson: Metaphysical Lyrics and Poems of the Seventeenth Century: Donne to Butler, Oxford and Clarendon Press, 1921). Según Eliot, Donne y los poetas barrocos no debían ser valorados 
poetas de finales del XVII la unión de la inteligencia y la imaginación que explica, en cierto modo, la penetración, la tensión trágica y lo que a veces encontramos de irritante en la poesía de Donne.

Una de las obras críticas más importantes de comienzos del XVIII: The Advancement and Reformation of Modern Poetry (1701) de John Dennos ya preconiza que la lengua debe tener vigor, un "estallido metálico" que refleje las cualidades varoniles de los "rough Britons". Pero no es sólo Dennis, sino que los críticos se interesan cada vez más en la lengua; admiran la sobriedad, concisión y claridad del inglés, pero se preocupan de la abundancia de consonantes, provenientes de su monosilabismo. ¿Cómo conciliar el orgullo nacional y el sentido de la armonía? Ese será el gran logro de Elizabeth Elstob con sus Rudimentos, en los que diserta sabiamente sobre los orígenes del inglés, señala que se deriva del gótico, del sajón y del escandinavo; que el pretendido exceso de consonantes no debe chocar ni a los oídos más delicados, citando para apoyar sus afirmaciones a Chaucer, Lydgate y Spencer. Veamos el inicio de la obra de Elstob, modelo de claridad y precisión:

GRAMMAR is the Art of Speaking and Writing, truly and properly. In Speaking we use certain Signs, which are necessary to discover our Thoughts to one another. These Signs, are Sound, and Voice.

But besides, Sound, and Voice, by which we are able to converse with one another when present; There are other Signs have been invented, where these Sounds cannot be heard, to supply the want of them in such manners, as that we may both converse with one another at a distance, and communicate our Thoughts to future Ages.

The first of these Signs belongs properly to Speech, or unwritten Discourse. The latter are made use of in Writing ${ }^{24}$.

\section{4. Judith Drake (h. 1696-post. 1723)}

Escritora y medico de profesión poco es conocido sobre la vida de esta mujer, que no aparece casi en ninguna enciclopedia o diccionario de

por su valor "barroco" o por cualquier otro rasgo de "mal gusto", sino en tanto que en esos poetas existe un valor inapreciable para la poesía contemporánea, que es esa sensibilidad "nodisociada". El problema que citamos está muy bien explicado en el libro de Juan Carlos Rodríguez: Teoría e Historia de la Producción Ideológica. Las primeras literaturas burguesas, Madrid, Akal Universitaria, 1990.

${ }^{24}$ El título completo de la obra es: The Rudiments of Grammar for the English-SaxonTongue, First: Given in English: With an Apology for the Study of Northern Antiquities. Being very useful towards the understanding our ancient English Poets, and other Writers. By Elizabeth Elstob. 
autores $^{25}$, y a la que ya se la considera como la autora de una obra que se había atribuido en un tiempo a Mary Astell: An Essay in Defence of the Female Sex, dado que la obra indicaba "written by a lady". Hija de un abogado de Cambridge se caso con James Drake, "fellow" de la Royal Society y del "College of Physicians", conocido pamfletario tory y dramaturgo. Él ayudó a Judith en la publicación y promoción de su tratado feminista". A la muerte de su marido, en 1707, ella editó un studio anatómico.

Durante muchos años atribuido a Mary Astell, An Essay in Defence of the Female Sex ${ }^{26}$ está escrito en un tono de humor en lugar del estilo serio utilizado por sus contemporáneos, defendiendo a la mujer contra la frecuente misoginia que la acusaba de frivolidad, vanidad e inconstancia. Drake satiriza la moral errática de los eruditos de "Country Squire" y del "Coffee-House Politician".

En Ensayo en defensa del sexo femenino vemos como el aprendizaje no se basaba sólo en el estudio de los textos clásicos, que por otro lado eran inaccesibles para la mayoría de las mujeres del siglo XVII. Esta obra animaba a las jóvenes a hacerse con obras literarias que tradicionalmente se habían asociado a lectoras femeninas; es decir, novelas, obras de teatro y poemas. Estos les proporcionaría sabiduría, humanidad, conductas de comportamiento y de conversación; "las auténticas razones por las que una niña de quince años podía ser considerada como madura por un niño de un año o por uno de veinte".

Desarrollando su argumento desde el racionalismo de la filosofía de Locke, Drake desmiente la existencia de ideas innatas y la distinción de sexos en las almas. La opresión intelectual de las mujeres estaba basada en la costumbre y en la contingencia, y no estaba justificada por la razón. Amparándose en las ideas del "estado de naturaleza" de Hobbes y de Locke, Drake señaló que, si se aceptaba que las diferencias fisiológicas entre los hombres y las mujeres eran la razón de una distribución de derechos desigual en la sociedad, esto debería continuar de modo que el más débil de ellos fuera el que mejor se adaptara a la labor intelectual.

En los últimos tiempos varios estudiosos han señalado que Judith Drake fue co-autora de Anthropologia Nova, haciendo especial hincapié sobre su punto de vista en lo relativo al proceso reproductivo; proceso éste

\footnotetext{
${ }^{25}$ Véase a este respecto: Uphaus, Robert W., and Gretchen M. Foster, eds. The "Other" Eighteenth Century: English Women of Letters, 1660-1800. East Lansing: Colleagues, 1991, autores que le dedican 10 páginas.

${ }_{26}$ An Essay in Defence of the Female Sex. In Which Are Inserted the Characters of a Pedant, a Squire, a Beau, a Vertuoso, a Poetaster, a City-Critick, \&c. In a Letter to a Lady. Written by a Lady. 1st edition. London: A. Roper, E. Wilkinson and R. Clavel, 1696.
} 
111

en el que pone de manifiesto el papel activo de la mujer tanto en la concepción como en la herencia. Parece cierto que realmente Drake tenía ciertos conocimientos médicos y que practicó la medicina sin tener cursada la carrera. En 1723 fue llamada por el Colegio Real de Físicos para defenderse de los cargos que se le imputaban por mala praxis; su defensa ante Hans Sloane, en ese momento presidente del Colegio Real de Físicos, demostró que Drake no había perdido ni un ápice del espíritu característico de sus trabajos anteriores, ya que respondió a uno de los que la acusaban de haberle administrado veneno que "el único veneno... administrado a sus oídos, era una demanda por cuestiones económicas".

Las secciones de las que consta la obra son las siguientes:

DEDICATION

PREFACE

To the Most Ingenious Mrs. - or her admirable Defence of Her Sex

To Madam - on the Occasion of her Essay, in Defence of her Sex.

The Lady's Answer

Section 1

"The Question I shall at present handle is, whether the time an ingenious Gentleman spends in the Company of Women, may justly be said to be misemploy'd, or not."

\section{Section 2}

"Our Company is generally by our Adversaries represented as unprofitable and irksome to Men of Sense, and by some of the more vehement Sticklers against us, as Criminal."

\section{Section 3}

"It remains then for us to enquire, whether the Bounty of Nature be wholly neglected, or stifled by us, or so far as to make us unworthy the Company of Men? Or whether our Education (as bad as it is) be not sufficient to make us a useful, nay, a necessary part of Society for the greatest part of Mankind."

\section{Section 4}

"After having granted so great a disparity as I have already done in the customary Education, and advantagious Liberties of the Sexes, 'twere Nonsense to maintain, that our Society is generally and upon all accounts as Beneficial, Improving and Entertaining, as that of Men."

\section{Section 5}


"Let us look into the manner of our Education, and see wherein it falls short of the Mens, and how the defects of it may be, and are generally supply'd."

\section{Section 6}

"To begin with Vanity, it is a Failing the greatest Part of Mankind are tinctured with, more or less."

\section{Section 7}

"Impertinence is a humour of busying ourselves about things trivial, and of no Moment in themselves, or unreasonably in things of no concern to us, or wherein we are able to do nothing to any Purpose."

\section{Section 8}

"Amongst the rest Dissimulation is none of the least Blemishes, which they endeavour to fix upon us."

\section{Section 9}

"Envy is the Parent of Calumny, and the Daughter of Jealousie."

\section{Section 10}

"We stand yet charg'd with Levity, and inconstancy, two Failings so nearly related, and so generally United, that it is hard to treat of 'em apart; we will therefore consider 'em briefly together."

\section{Section 11}

"There are the most considerable Imperfections, or at least those, which with most Colour of Reason are charg'd upon us, as general Defects; and I hope, Madam, I have fairly shown, that the other Sex are both by Interest and Inclination more expos'd, and more Subject to 'em than we, Pride, Lust, Cruelty, and many more, are by the Declaimers against us thrown into the Scale to make weight and bear us down, but with such manifest Injustice, that without giving myself any further trouble, I dare appeal to any reasonable Man, and leave him to decide the Difference.

\section{5. Lady Mary Wortley Montagu (1689-1762)}

Escritora, feminista temprana, aristócrata, persona muy conocida en la alta sociedad inglesa y famosa asimismo por haber introducido la inoculación contra la viruela, Montagu es recordada en la actualidad por sus cartas, sobre todo las que escribió desde Turquía, descritas por Billie Melman como "the very first example of a secular work by a woman about the Muslim Orient". Mary Pierrepont era la menor de ocho hijos de Evelyn Pierrepont (que llegó a ser conde de Kingston en 1690, marqués de Dochester en 1706 y duque de Kingston en 1715) Al morir su madre, 
teniendo ella 13 años, fue llevada a casa de su abuela materna, convirtiéndose en una muchacha brillante y precoz al aprender muy pronto latín y trabando amistad con la principal referencia femenina de su época en lo que concierne a la defensa de los derechos de la mujer: Mary Astell. También gozó de la amistad de grandes figuras literarias: Addison, Steele, Congreve y Garth. Hacia 1710 es cortejada por Edward Wortley Montagu, intercambiando una gran correspondencia con él, con quien se fugará antes de casarse en 1712 .

Tras la llegada al trono de los Hannover, en 1714, su esposo es nombrado "Junior Commisioner of the Treasury", quedándose a vivir en Londres; allí conoce a Pope y Gay, escribiendo junto con este último algunas "town eclogues", tres de las cuales son publicadas sin permiso de autor por Edmund Curll como Court Poems, 1716.

En 1715 enferma de viruela, dolencia de la que ya había muerto un hermano. Mary hará inocular la enfermedad a sus propios hijos y a su regreso tratará de introducir en Europa esta práctica, encontrando un gran número de prejuicios entre médicos y científicos, lo que hizo retrasar sesenta años la adopción de la vacuna en occidente. Su esposo es nombrado Embajador en Turquía, 1717, acompañándolo ella a Constantinopla. Alexander Pope se enamora de ella y le dedica numerosos poemas, entre ellos Eloisa to Abelard, pero luego la atacará duramente. En 1739 se enamora perdidamente de Francesco Algarotti, un joven escritor al que sigue a Italia; curiosamente, aunque nunca estableciera una relación duradera con él permaneció amistosamente separada de su esposo, volviendo a Inglaterra sólo a la muerte de éste en 1761 y muriendo un año más tarde. Horace Walpole, de viaje en Florencia, en 1740, describirá su vida como "impudence, avarice, and absurdity".

Un año después de su muerte sus Cartas desde la embajada de Turquía consolidarán su reputación literaria, aunque también está considerada como una buena poetisa. En 1837, Lord Wharncliffe edita sus Letters and Works. Sus poemas solo han recibido la atención y el reconocimiento de la crítica desde muy recientemente, aunque son buenos ejemplos de sátiras femeninas contra el narcisismo femenino y la arrogancia masculina, así como de temas muy variados. Veamos un poema sobre la vanidad en la mujer:

THE LADY'S RESOLVE

(Written on a window, soon after her marriage, 1713)

Whilst thirst of praise and vain desire of fame, In every age is every woman's aim;

With courtship pleas'd, of silly toasters proud, 
Fond of a train, and happy in a crowd;

On each proud fop bestowing some kind glance,

Each conquest owing to some loose advance;

While vain coquets affect to be pursued,

And think they're virtuous, if not grossly lewd:

Let this great maxim be my virtue's guide;

In part she is to blame that has been try'd-

He comes too near, that comes to be deny'd.

\section{LA DECISIÓN DE LA SEÑORA}

(Escrito en una ventana, poco después de su matrimonio, 1713)

Cuando a todas edades el fin de la mujer

es la sed de alabanza y la ambición de fama;

por cortejo alagada, por adulador loada,

de admirador amante y feliz entre gentes;

viendo con complacencia a cualquier petimetre,

debiendo la conquista a insinuaciones vanas;

mientras vanas coquetas simulan el cortejo,

pensando ser virtuosas, si no libidinosas;

permite que esta máxima de mi virtud sea guía:

en gran parte es culpable aquella a quien persiguen-

el que mucho se acerca, acaba rechazado.

\section{CONCLUSIÓN}

Mary Astell representa, no sólo en los denominados 'estudios de género', sino en la historia social de la literatura, todo un ejemplo de abnegación, firmeza y valentía para defender y llevar a cabo una idea sin viso algunos de egoísmo y con una generosidad extrema. Ejemplos como el suyo aparecen con cierta asiduidad en la historia de la humanidad, jalonada de acciones llevadas a cabo por seres humanos extraordinarios (en este caso del sexo femenino), de seres que con su esfuerzo han contribuido a que la humanidad se vaya liberando poco a poco de unas farragosas cadenas que únicamente se sueltan movidas por la generosidad y la solidaridad.

Su obra será trascendental para la futura emancipación de las mujeres, contribuyendo también -aunque en menor medida- al despegue del género poético femenino, del mismo modo que otras autoras contribuyeron al desarrollo del teatro o del género narrativo, produciéndose estos avatares generalmente tras una discusión sobre la igualdad, la diferencia, la similitud, etc. de los sexos ${ }^{27}$.

${ }^{27}$ Me viene a la mente por ejemplo el término 'New Woman fiction', usado para describir a finales del XIX los escritos que concedían especial relevancia a las ideas y acciones de la 'New Woman', frase acuñada por la novelista Marie Louise de la Ramée (1839-1908), más conocida 
REFERENCIAS BIBLIOGRÁFICAS

ANDERSON, Bonnie S., Judith P. Zinsser y Judith P Zinsser, Historia de las mujeres: Una historia propia, Barcelona, Crítica S. L., 2009 (trad. de Teresa Camprobón y Beatriz Villacañas: A History of Their Own).

APETREI, Sarah, Women, Feminism and Religion in the Early Enlightenment England, Cambridge University Press, 2010.

BACKSCHEIDER, Paula R., Eighteenth-Century Women Poets and Their Poetry.Inventing Agency, Inventing Genre, Baltimore: The Johns Hopkins University Press, 2008.

BlAIN, Virginia, et alii (eds.), "Thomas, Elizabeth", The Feminist Companion to Literature in English. New Haven and London: Yale UP, 1990.

BOUCHIER Richardson Georges, William and Elizabeth Elstob, the learned Saxonists, Newcastle, 1847.

BROAD, Jacqueline, "Mary Astell on Virtuous Friendship", Parergon, Volume 26, Number 2, Australian and New Zealand Association of Medieval and Early Modern Studies, 2009, pp. 65-86.

DeLunA, D. N., "Mary Astell: England's first feminist literary critic", Women's Studies, Volume 22, Issue 2, 1993, pp. 231-242.

Evans, Sara M., Personal Politics: The Roots of Women's Liberation in the Civil Rights Movement \& the New Left, New York: Vintage Books, 1979.

GREER, Germaine, et alii (eds.), "Elizabeth Thomas", Kissing the Rod: an anthology of seventeenth-century women's verse, Farrar Staus Giroux, 1988.

GRUNDY, Isobel, Lady Mary Wortley Montagu: Comet of the Enlightenment, Oxford University Press, USA, (new edition 2001).

Ferguson, Moira, First Feminists: British Women Writers 1578 - 1799, Bloomington: Indiana University Press, 1985.

HALSBAND, Robert, The Life of Lady Mary Wortley Montagu, Oxford: Clarendon Press, 1956.

HUFF Collins, Sarah, Elizabeth Elstob: a biography, Thesis-Indiana University, 1970.

Lady MARY WORTLEY MonTAGu, Poetical Works, edited by Isaac Reed, 1768. , The Complete Letters of Lady Mary Wortley Montagu, 3 vols, edited by Robert Halsband, Oxford: Clarendon Press, 1965-67.

como "Ouida" (mala pronunciación infantil de 'Louise', al responder al artículo de Sarah Grand (seudónimo de la novelista Frances Elizabeth Bellenden Mcfall (1854-1943), "The New Aspects of the Woman Question", en 1894. 
Romance Writings, edited by Isobel Grundy, Oxford: Clarendon Press, 1996.

, Essays and Poems and Simplicity, a Comedy, edited by Isobel Grundy, Oxford: Clarendon Press, 1977 (revised 2nd 1993).

LERNER, Gerda, The Creation of Feminist Consciousness: from the Middle Ages to Eighteen-Seventy, Oxford University Press, 1993.

MANDER, W. J., Harris, The Philosophy of John Norris, Manchester College, Oxford University, 2008.

McWHIR, Anne, "Elizabeth Thomas and the Two Corinnas: giving the woman writer a bad name", ELH, March 22, 1995.

SmITH, Hilda L., Reason's Disciples, Seventeenth-Century English Feminism, Urbana: University of Illinois, 1982.

SMITH, Hannah, "English 'feminist' writing and Judith Drake's An Essay in Defence of the Female Sex (1696)", The Historical Journal, vol. 44, 3, Cambridge University Press, 2001, pp. 227-247.

UpHAUS, Robert W., and Gretchen M. Foster (eds.), The "Other" Eighteenth Century: English Women of Letters, 1660-1800. East Lansing: Colleagues, 1991.

WALTERS, Margareth, Feminism: a Very Short Introduction, Oxford University Press, 2005. 